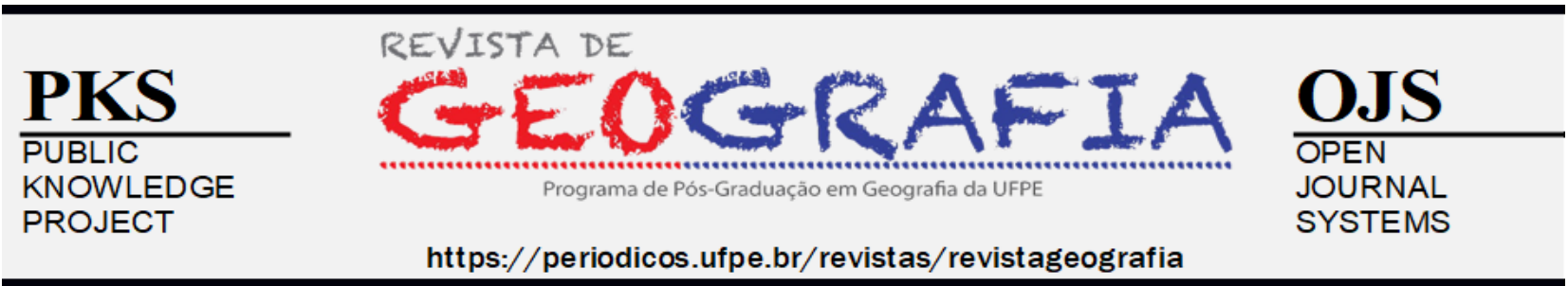

\title{
MAPEAMENTO DE SITUAÇÕES DE TRABALHO NO CAMPO MARANHENSE: APONTAMENTOS E TIPOLOGIAS A PARTIR DE PESQUISAS ARQUIVISTAS E ICONOGRÁFICAS
}

\author{
Laiz Algave Garcez ${ }^{1}$, Matheus Sousa Barros ${ }^{2}$, Sávio José Dias Rodrigues ${ }^{3}$ \\ ${ }^{1}$ Universidade de São Paulo (USP); E-mail: laizgarcez@gmail.com; Orcid: http://orcid.org/0000-0003-0191-7462 \\ ${ }^{2}$ Universidade Estadual de Campinas (UNICAMP); E-mail: matheusbarros04@gmail.com; Orcid: \\ http://orcid.org/0000-0003-0102-6520 \\ ${ }^{3}$ Doutor em Geografia pela Universidade Federal do Ceará (UFC); Docente pela Universidade Federal do Maranhão \\ -UFMA; E-mail: saviodiasbr@gmail.com; Orcid: http://orcid.org/0000-0002-4576-3621
}

Artigo recebido em 16/09/2021 e aceito em 18/09/2021

\begin{abstract}
RESUMO
Nesse artigo iremos discutir o papel da mídia na construção do imaginativo da pessoa que é escravizada, formar o perfil da situação de trabalho escravo contemporâneo maranhense. Identificar algumas narrativas que ajudam a construir o imaginário do trabalhador escravo contemporâneo presente na mídia brasileira, em especial na mídia maranhense. A análise de notícias é importante para entender o que está sendo passado para a sociedade. Essa pesquisa busca entender através meios de notícias (portais de notícias online) como lugar de disputas discursivas que apresentam efeitos de recepção de um grupo social especifico, pois, o jornal tem um papel essencial na construção de narrativas. A representatividade na mídia é construída por vários discursos institucionais e organizados por uma normatização comum ao próprio jornalismo. A partir da análise dessas notícias poderemos perceber como esse trabalhador é representado para a sociedade, se ele recebe ou não o nome, se é tratado de forma digna ou apenas mais um número a ser inserido no sistema. Se as notícias analisam as situações que esses trabalhadores são levados a se encontrar em situação de tal vulnerabilidade. Se as matérias jornalísticas se importam em proteger os trabalhadores ou os escravagistas. Essa analise pode nos levar a entende como a grande mídia vê e representa esses trabalhadores e qual o tipo de narrativa está sendo entregue a sociedade e qual a imagem pintada por tal sobre essa exploração, que ocorre tanto no campo como na cidade, que é visto com maus olhos pela população, não só brasileira.
\end{abstract}

Palavras-chave: Mídia; Discurso; Trabalho Escravo; Maranhão.

\section{MAPPING WORK SITUATIONS IN CAMPO MARANHENSE: NOTES AND TYPOLOGIES FROM ARCHIVAL AND ICONOGRAPHIC RESEARCH}




\begin{abstract}
In this article we'll discuss the role of media in the imaginative construction of slavere people, form and profile the situacion of Maranhão's contemporane slave labor. identify some narratives that help to build a imaginative of contemporaine slave labour present in brasilian media, in special of marnahences's media. The analysis of news is important for understanding what is being said to the society. This research seeks to understand through news (online news portals) as a place of speech dispute that present effects of recepcion in specific social groups, because a newspaper has an essential role in the construction of narratives. The representativeness in midia is built by a multiple institucionals speech and organised for a normalization ordinary of newspaper itself. From the analyses of the news we could perceive how the workers a represent to the society, if he is given a name, if he is treated in a dignified way or just another number in the system. If the news analysed the condition that the works are taken to find themselves in a vulnerable situacion. If the news articles care about protecting the works or the slever's owners. This analysis can take us to understand how the media see and represent this work. What type of narrative is being sent to the society and which picture is painted by them of this exploration that happens over the countryside and the cities, that is seen as wrong by the population, and not just the brasilians.
\end{abstract}

Keywords: Media; Speech; Slave Work; Maranhão.

\title{
MAPEO DE SITUACIONES DE TRABAJO EN CAMPO MARANHENSE: APUNTES Y TIPOLOGÍAS DE LA INVESTIGACIÓN ARCHIVÍSTICA E ICONOGRÁFICA
}

\section{RESUMEN}

En este artículo discutiremos el papel de los medios de comunicación en la construcción del imaginativo de la persona esclavizada, para formar el perfil de la situación contemporánea del trabajo esclavo en Maranhão. Identificar algunas narrativas que ayuden a construir la imaginación del esclavista contemporáneo presente en los medios brasileños, especialmente en los medios de Maranhão. El análisis de noticias es importante para comprender lo que se transmite a la sociedad. Esta investigación busca entender a través de los medios informativos (portales informativos en línea) como un lugar de disputas discursivas que presentan efectos de recepción de un grupo social específico, ya que el periódico tiene un papel fundamental en la construcción de narrativas. La representación de los medios está construida por varios discursos institucionales y organizada por una estandarización común al periodismo mismo. A partir del análisis de estas noticias podremos ver cómo este trabajador está representado ante la sociedad, si recibe o no el nombre, si es tratado con dignidad o simplemente un número más para ser insertado en el sistema. Si la noticia analiza las situaciones que estos trabajadores se encuentran llevados a encontrarse en una situación de tal vulnerabilidad. Si las historias periodísticas se preocupan por proteger a los trabajadores o a los esclavistas. Este análisis puede llevarnos a comprender cómo los grandes medios ven y representan a estos trabajadores, qué tipo de narrativa se está entregando a la sociedad y cuál es la imagen que pintan sobre esta explotación, que se da tanto en el campo como en la ciudad, que Se ve con malos ojos por la población, no solo brasileña.

Palabras clave: Medios; Habla; Trabajo Esclavo; Maranhão

\section{INTRODUÇÃO}


O Brasil foi um dos últimos países a abolir a escravidão, em 1888. Porém a criminalização legal da escravização de pessoas não impediu que o mesmo acontecesse, e em 1930 a Organização Internacional do Trabalho reconheceu a existência do trabalho análogo a escravidão no Brasil. Esse fenômeno foi abafado, silenciados para não sujar o nome do país no cenário internacional.

Em 1995, o Estado brasileiro reconheceu formal e politicamente a persistência do trabalho escravo em seu território. Em 2003, no aspecto legislativo se teve o advento do decreto $\mathrm{n}^{\mathrm{o}} 10.803$, um marco histórico no combate a escravidão contemporânea. $\mathrm{O}$ instrumento normativo modificou a redação do artigo 149 do Código Penal, extinguindo o tipo penal aberto e dando vez a quatro hipóteses de trabalho escravo.

Nos anos 1960, circulava na imprensa brasileiras notícias de trabalhadores escravizados, escravidão branca, mão de obras como mercadorias, aliciamento, formação de quadrilha, tráfico. E nessas reportagens se dava um grande enfoque no trabalho da Polícia Federal e aos motoristas e arregimentadores, sem mencionar quem bancava esse tipo de crime ou quem comprava essas pessoas escravizadas e para onde essas pessoas eram levadas.

Nesse artigo iremos discutir o papel da mídia na construção do imaginativo da pessoa que é escravizada, a formação do perfil da situação de trabalho escravo contemporâneo maranhense. Identificar algumas narrativas que ajudam a construir o imaginário do trabalhador escravo contemporâneo presente na mídia brasileira, em especial na mídia maranhense. A análise de notícias é importante para entender o que está sendo passado para a sociedade. Essa pesquisa busca entender através dos meios de notícias (portais de notícias online) como lugar de disputas discursivas que apresentam efeitos de recepção de um grupo social especifico, pois, o jornal tem um papel essencial na construção de narrativas.

Esse artigo surge do projeto de pesquisa, realizado pelo Núcleo de Pesquisas Geográficos NEGO, sobre Trabalho Escravo e Questão Agrária no "Novo Nordeste" brasileiro. Mais especificamente do plano de trabalho sobre Trabalho escravo e Mídia. Tendo o Maranhão como estado que mais exporta mão de obra escravizada, a aparição de notícias que contam histórias de maranhenses regatados no estado e fora dele ocorre com certa frequência. E essas histórias são contados por veículos de comunicação que tem pautas e ideologias e próprias. Nosso recorte surge de parte da pesquisa que abrange vários jornais do estado, porém para esse artigo em especifico, será observado apenas as notícias do portal online do "O Imparcial”, que possui também circulação por meio físico. 
A proposta de pesquisa apresentada aqui busca o diálogo entre diversos campos científicos. Essa tentativa se dá por entender que o real não obedece às divisões disciplinares. Por que a dialética nos permites meios técnicos de tentar analisar a totalidade, o conhecimento é totalizante e a atividade humana, em geral, é um processo de totalização que nunca alcança uma etapa (Konder, 1985)

Por isso, a leitura de autores como Neide Esterci (1994), em Escravos da Desigualdade: um estudo sobre o uso repressivo da força de trabalho, onde ela escreve sobre a compreensão das atitudes das pessoas contra as quais são praticadas forças extremas de exploração e dominação, baseada na violência física e/ou simbólica e referidas como formas atuais de escravidão. A luz da autora Flavia Moura (2016), que escreve sobre a construção do imaginário social do trabalho escravo realizado pelo jornalismo televisivo, ou ainda como o entendimento da dignidade humana é fundamento de partida para a proteção ao ser humano, que tem no artigo o trabalho escravo contemporâneo sob a ótica da pessoa humana do Bismark Diniz e da Mariana Barros.

\section{TRABALHO ESCRAVO CONTEMPORANEO}

O Trabalho escravo foi oficialmente abolido em 1888. Em 1930 a Organização Internacional do Trabalho aprovou a Convenção 29 que reconheceu a existência do trabalho escravo análogo ao de escravo. Desde a constituição de 1940, o brasil prevê o crime de redução do homem a condição análoga à de escravo porem o conceito era muito aberto, não detalhando o que seria submeter alguém a condição análoga a de escravo. Em 1995, o Estado Brasileiro reconheceu formalmente a persistência do trabalho escravo em seu território. Em 2003, no aspecto legislativo se teve o advento da Lei $\mathrm{n}^{\mathrm{o}}$ 10.803. Um marco histórico no combate a escravidão contemporânea, que modificou a redação do art. 149 do Código penal, ao especificar quatro hipóteses de trabalho escravo:

1. Submissão a trabalhos forçados: Quando a violação de direitos fundamentais fere a dignidade do trabalhador e coloca em risco sua saúde e sua vida. Costuma ser um conjunto de elementos irregulares, como alojamentos precários, péssima alimentação, falta de assistência médica, saneamento básico e água potável.

2. Submissão a jornada exaustiva: Quando o trabalhador é submetido a esforço excessivo, sobrecarga ou jornadas extremamente longas e intensas que acarretam danos à sua saúde, segurança ou mesmo risco de morte.

3. Sujeição a condição degradantes de trabalho: Quando a violação de direitos fundamentais fere a dignidade do trabalhador e coloca em risco sua saúde e sua vida. Costuma ser um 
conjunto de elementos irregulares, como alojamentos precários, péssima alimentação, falta de assistência médica, saneamento básico e água potável.

\section{Restrição da locomoção em razão de dívidas contraídas como propósito e/ou} empregador, ou seja, servidão por dívida: Quando a pessoa é mantida no serviço através de fraudes, isolamento geográfico, ameaças e violências físicas e psicológicas, tendo sua liberdade violada.

A escravidão contemporânea é caracterizada pelo trabalho forçado, constituindo-se no absoluto controle de uma pessoa sobre a outra, ou de um grupo de pessoas sobre outro grupo social, no qual os trabalhadores são submetidos a condições degradantes de trabalho em um cenário de isolamento geográfico, dívidas fraudulentas e/ou a presença de guardas armados, evidenciando o desrespeito e a violação aos direitos humanos.

O trabalho escravo é uma das piores formas de degradação humana e social que assolam o mundo em proporções variadas. De acordo com os indicadores globais levantados pela OIT estimase que 12,3 milhões de pessoas são vítimas de trabalho forçado, apontando maior concentração na América Latina e Caribe com cerca de 1.320 .000 vítimas. A realidade não exclui o Brasil dos aludidos índices, outrossim, conforme estimativa realizada pela OIT cerca de 25.000 pessoas são mantidas em condições análogas as de escravidão. Os casos de trabalho escravo têm sido encontrados principalmente na pecuária $(80 \%)$ e na agricultura $(17 \%)$. Os trabalhadores são escravizados na derrubada de matas nativas para formação de pasto, na produção de carvão para a indústria siderúrgica, na preparação do solo para o plantio das sementes, dentre outras atividades agropecuárias.

O trabalho escravo contemporâneo é uma exploração mais comum do que se pensa. No Brasil o trabalho escravo baseado na mão de obra negra foi oficialmente abolido em 1888, porem em 1930 a OIT (Organização Internacional do Trabalho), denunciava que no país ainda se persistia a pratica do trabalho escravo, agora denominado trabalho análogo à escravidão. Desde de a constituição de 1940, o Brasil prevê o crime de redução do homem á condição análoga à de escravo. 
Figura 01: Mapeamento dos municípios de maior incidência trabalho escravo no Maranhão - anos de 2003 a 2017

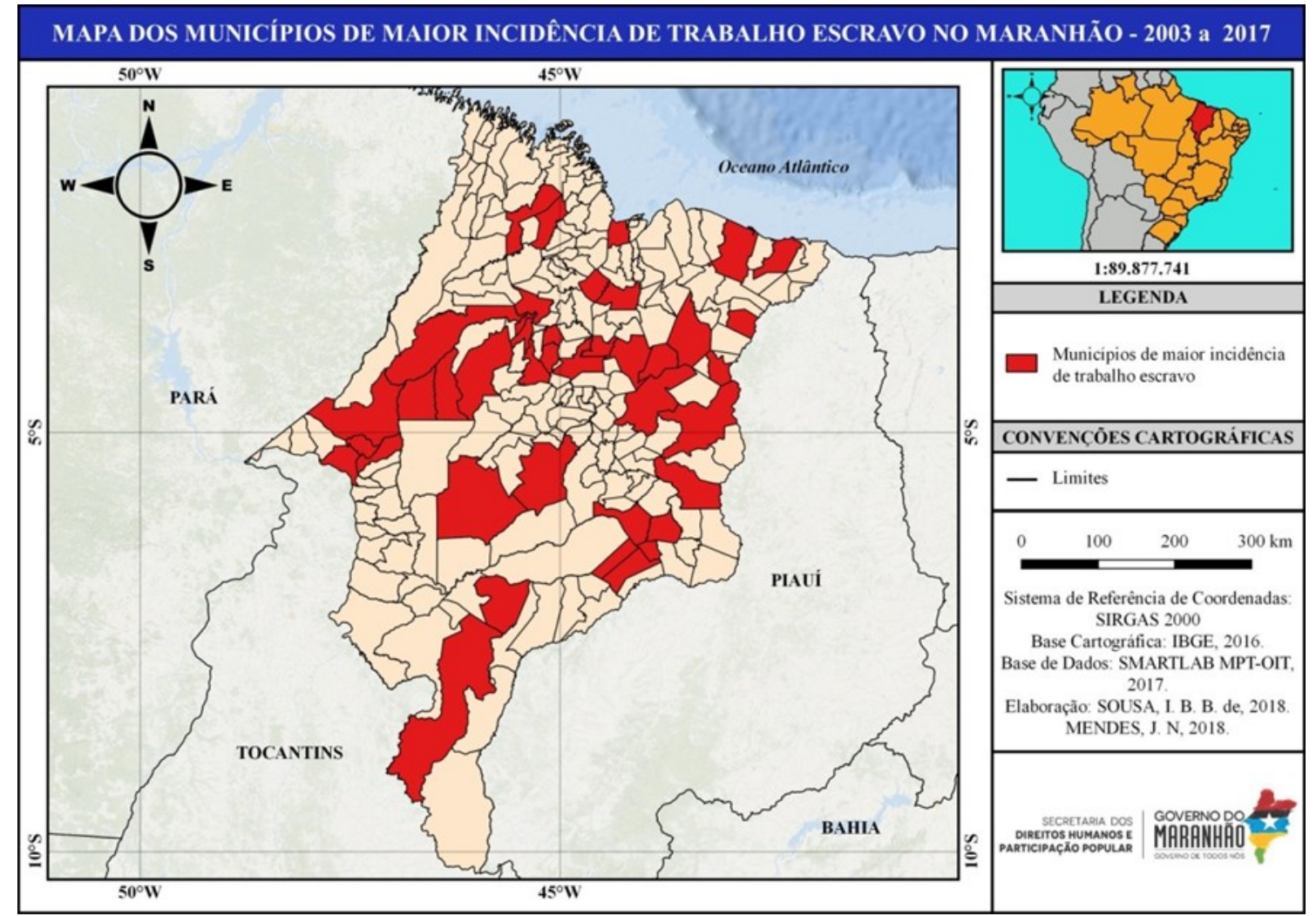

Fonte: Relatório do Trabalho Escravo no Maranhão, Secretária de Direitos Humanos e Participação Popular (SEDHPOP), 2018.

A formação histórica da economia brasileira está assentada no trabalho escravo, sempre permeou as relações sociais no Brasil desde os primórdios da colonização até a determinados espaços de desenvolvimento capitalista (SEVERO, 2016). Porem a ideia de trabalho escravo no meio do sistema econômico como o capitalismo, que se considera liberal e usa do consumo de trabalhadores assalariados, pode ser vista como contraditórias. O "trabalho escravo moderno" aparece [...] como contradição do modo de produção capitalista, mas, ao mesmo tempo como medida necessária de potencialização da acumulação de capital a parti da reprodução da acumulação primitiva de capital (RODRIGUES, 2017, p. 254).

O Maranhão é um dos grandes exportadores de mão de obra escrava para o restante do país. A concentração de terras, a estrutura de poder proveniente do domínio da produção e o acesso às condições de sobrevivência a parte da política de acesso as terras.

O planejamento sócio-econômico do Estado do Maranhão caracterizou-se pela hegemonia dos processos produtivos num mercado globalizado. Com o foco das ações centradas na produção rural, fez do agronegócio a estratégia catalisadora das atenções políticas e dos investimentos em infraestrutura e custeio da produção. A estratégia de dinamização da economia inspirada neste modelo priorizou o uso intensivo de tecnologia de produção e transporte, absorvendo pouca mão-de-obra, fazendo surgir a categoria de assalariados rurais 
e contribuindo para aumentar o contingente de desempregados nas periferias urbanas, uma vez que os impactos ambientais e sociais no campo provocaram a expulsão de posseiros e estimulou a venda de pequenas propriedades, facilitando o avanço dos grandes empreendimentos agropecuários e agro-industriais. $\mathrm{O}$ cenário exposto acima criou um ambiente favorecedor da precarização das condições e relações de trabalho, que tem gerado o problema do trabalho escravo e sua permanência, fazendo do Maranhão o Estado com maior número de trabalhadores vítimas desse crime no Brasil. (II PLANO ESTADUAL DE ERRADICAÇÃO DO TRABALHO ESCRAVO NO MARANHÃO, 2012, p.9).

É nesse contexto que se evidencia a reprodução do trabalho escravo. O trabalho escravo tem se apresentado como uma contradição do desenvolvimento do capitalismo brasileiro, sobretudo, a partir da ideia de modernização da economia do país, assim sendo uma forma de exploração do trabalho aparentemente contrária ao esperado. Entretanto, sua continua aparição, bem como o aumento de suas ocorrências na cidade, tem demonstrado que o trabalho escravo não é contrário à modernização econômica. Ele é parte do próprio desenvolvimento do modo de produção. A ideia de que o trabalho escravo caminha em consonância com o modo de produção capitalista tem sido debatida na literatura a partir de várias posturas, desde os mais moderados que consideram que o seu uso é circunscrito a ramos da produção que não puderam utilizar de tecnologia, as denominadas "franjas" do sistema (SAKAMOTO, 2011), até os que avançam para pensar o trabalho escravo como estratégia concorrencial de manutenção de taxas de lucro do modo de produção (TRINDADE, 2011).

\section{MÍDIA COMO INSTITUIÇÃO SOCIAL}

A representatividade na mídia é construída por vários discursos institucionais e organizados por uma normatização comum ao próprio jornalismo. À mídia faz parte da sociedade. Dessa forma, entendemos a mídia como uma instituição constituinte de vida cotidiana (ESCOSTEGUY, 2013). Silverstone (2002) afirma que a mídia, apesar de sua diversidade e sua flexibilidade, ainda se apresenta como uma forma dominante de comunicação, capaz de constranger culturas locais, mesmo que não as subjugue.

\footnotetext{
No caso as narrativas midiáticas podem construir ou legitimar representações já construídas pelo próprio grupo, aparte de outras instâncias sociais, tais como a famílias, os círculos religiosos, os movimentos sociais locais ou mesmo as redes de vizinhança desses trabalhadores. (MOURA, 2016, p.31).
}

Ao estudarmos mídia, estamos lidando com seres humanos e sias comunicações, com linguagem e fala, com dizer e o dito, com reconhecimento e mal - reconhecimento e com s mídis vista como intervenção técnicas e políticas nos processos de compreensão (SILVERSTONE, 202, 
P.19). O autor nos convida a analisar a mídia como uma dimensão social e cultural, porém também política e econômica; estudar sua onipresença e sua complexidade, como parte da textura a experiência. Procuramos entender como a mídia participa da vida social e cultural contemporânea (MOURA, 2016).

[...] a mídia faz parte da sociedade, está inserida nela como estão os postos de saúde, as defensorias públicas, os estádios esportivos, por exemplo. É uma das instituições da sociedade, e congrega os múltiplos dispositivos através dos quais essa sociedade produz e faz circular suas informações e representações. De resto, a mídia constitui talvez a instituição que melhor caracteriza o cenário contemporâneo; a fase da nossa sociedade, nosso comportamento, nossas ações são hoje o que são por que dispomos de tais meios, espaços, instrumentos para nos informarmos, nos exprimirmos, formatarmos nossas ações e nosso cotidianos. A mídia é o espaço privilegiados no qual a sociedade fala consigo mesmo, a propósito de si mesma. (FRANÇA, 2012, p. 11-12).

A vista disso, o jornalismo só existe como profissão e tem um papel na sociedade pois, trabalha para fornecer a proporcionar à população de informações que contribua com a promoção de sua cidadania. Essa característica constitucional do jornalismo faz com que ele tenha entre os seus fundamentos principais elementos a independência, o compromisso coma a verdade, a lealdade com os cidadãos e o dever de apresentar as notícias de forma proporcional, e apontam Kovach e Rosenstiel (2004). Por tanto, “A principal finalidade do jornalismo é fornecer aos cidadãos as informações de que necessitam para serem libres e se autogovernar" (KOVACH e ROSENSTIEL, 2004, p. 31).

Nelson Traquina diz que o jornalismo é o quarto poder, pois tem a capacidade de investigar os outros poderes e de poder divulgar informações que dão instrumentos para a existência de uma democracia, por que tem uma ligação direta com a sociedade. O poder do jornalismo e dos jornalistas aponta para a importância das suas responsabilidades sociais. A afirmação do reconhecimento das suas responsabilidades, por parte dos jornalistas também por parte das empresas jornalísticas, não é possível reduzindo as notícias a uma simples mercadoria, e ignorando a existência dos ideais mais nobres do jornalismo, que fornecem uma manta de legitimidade ao negócio. (TRAQUINA, 2005, p.207-208).

\section{ANALISE DAS REPORTAGENS}

As 52 notícias foram encontradas de 11 portais de notícias diferentes, sendo que sua maioria são de jornais do estado do Maranhão. Onde o jornal O Impacial e O Jornal Pequeno têm grande parcela das notícias analisadas. Entre o período de 2013 a 2019 foram feitas. Levando em 
consideração 4 categorias de analises: Nomenclatura; Dignidade Humana; Empreendedor/escravagista e Localidade do resgate.

Figura 2 - Levantamento geral de jornais e portais de notícias com citações relacionadas ao trabalho escravo entre os anos de 2013 a 2019 no Maranhão

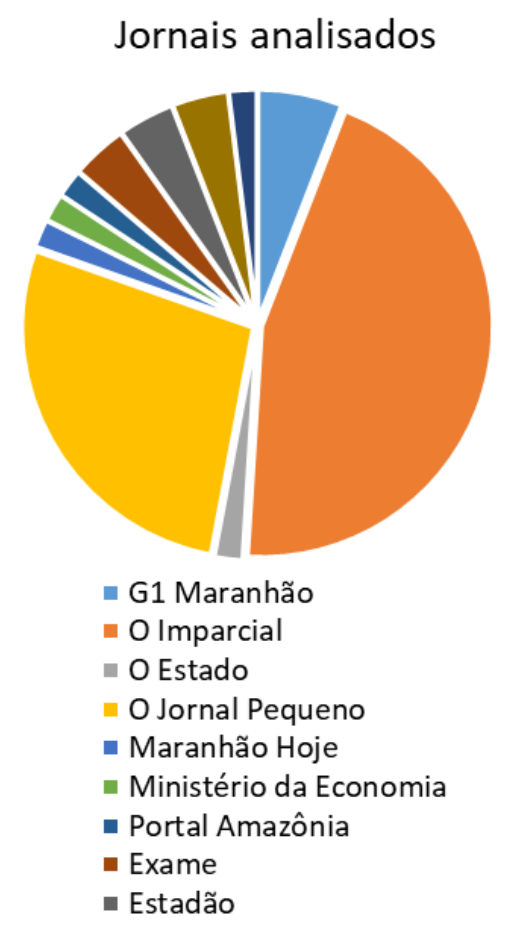

Fonte: Garcez (2019)

A primeira linha de análise é a Nomenclatura. O trabalho escravo contemporâneo recebe vários nomes como "escravidão", "semiescravidão", "trabalho forçado" e outros. Essa multiplicidade e variação dos termos utilizado indica que os critérios de classificação estão em discursão tanto no campo políticos -ideológico quanto no que diz respeito ao seu enquadramento na legislação trabalhista e no código de direitos humanos.

Identificar os significados dos diferentes usos dos nomes, é identificar as diferentes lutas por de trás deles, a dominação que ocorre ao usar esses termos de forma repressiva e da exploração. Definir o tipo de relação é tão importante que dependendo da legitimação da relação, de sua definição de acordo com as leis, até a escolha dos canais governamentais para onde encaminhar as denúncias, elas podem passar por meras infrações das leis trabalhistas (onde a lei é branda) que é encaminhado para o ministério do Trabalho, até como infrações do Código Penal. 
Figura 3: Analise das reportagens nos jornais e portais de notícias através da nomenclatura utilizada

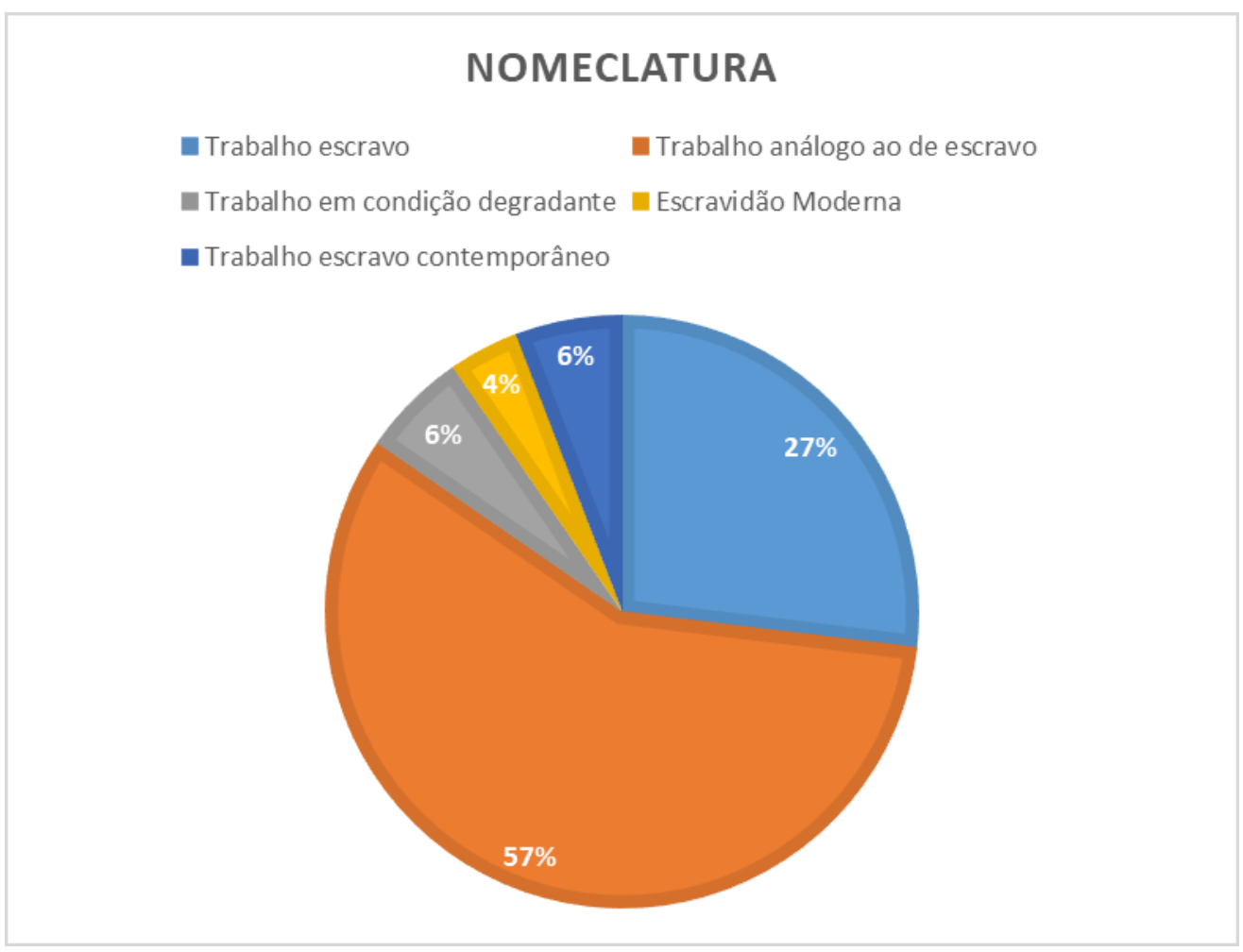

Fonte: Garcez (2019).

A segunda linha de análise foi a da Dignidade humana. No iluminismo o filósofo Immanuel Kart, defendia a partir de uma perspectiva humanista, que o ser humano é dotado de valor intrínseco, representando um fim em si mesmo, não podendo ser tratado como objeto ou como meio para a realização de interesses alheios. O homem não pode ser usado como meramente meio, que apenas tenham a intenção de submete-lo e explorá-lo, uma vez que isso degradaria seu valor intrínseco, ou seja, sua dignidade. Essa concepção que é a que deve imperar no tratamento ao trabalhador, o de vedação da coisificação.

A dignidade foi incorporada à importantes documentos internacionais como por exemplo Carta das Nações Unidas (1945) e a Declaração Universal dos Direitos Humanos (1948). A constituição de 1988 que traz em seu artigo $3^{\circ}$, inciso III, a dignidade da pessoa humana como um dos fundamentos da República Federativa do Brasil. Tornando-se um fundamento do estado de direito e valor supremo a ser protegido, irrenunciável e inalienável.

A ideia de dignidade não tem conceito delineado. A ideia de dignidade está fortemente ligada a uma concepção de política e de cultura. Sofrendo mutações de acordo com a perspectiva de determinada sociedade, sendo um conceito de contornos vagos e imprecisos. Mas a ideia de dignidade está fortemente ligada a ideia de comunidade, ou seja, ligado a questões culturais. $\mathrm{O}$ 
reconhecimento dos direitos do homem se deu a partir de sua universalização e de sua multiplicação. A promoção do trabalho descente está ligada a dignidade da pessoa humana.

O trabalho descente, então, é um conjunto mínimo de direitos do trabalhador que corresponde à existência de trabalho; a liberdade de trabalho; a igualdade de trabalho; o trabalho em condições justas incluindo a remuneração e que preservem sua saúde e segurança; a proibição do trabalho infantil; a liberdade sindical; e a proteção contra os riscos sociais (FILHO, 2010, p.52).

A conceituação apresentada pela OIT para a figura do trabalho forçado diz que a expressão trabalho forçado ou obrigatório designará todo trabalho ou serviço exigido de um indivíduo sob ameaça de qualquer personalidade e para o qual ele não se ofereceu de espontânea vontade.

Figura 4: Analise das reportagens nos jornais e portais de notícias através da dignidade humana dos trabalhadores em situação de vulnerabilidade

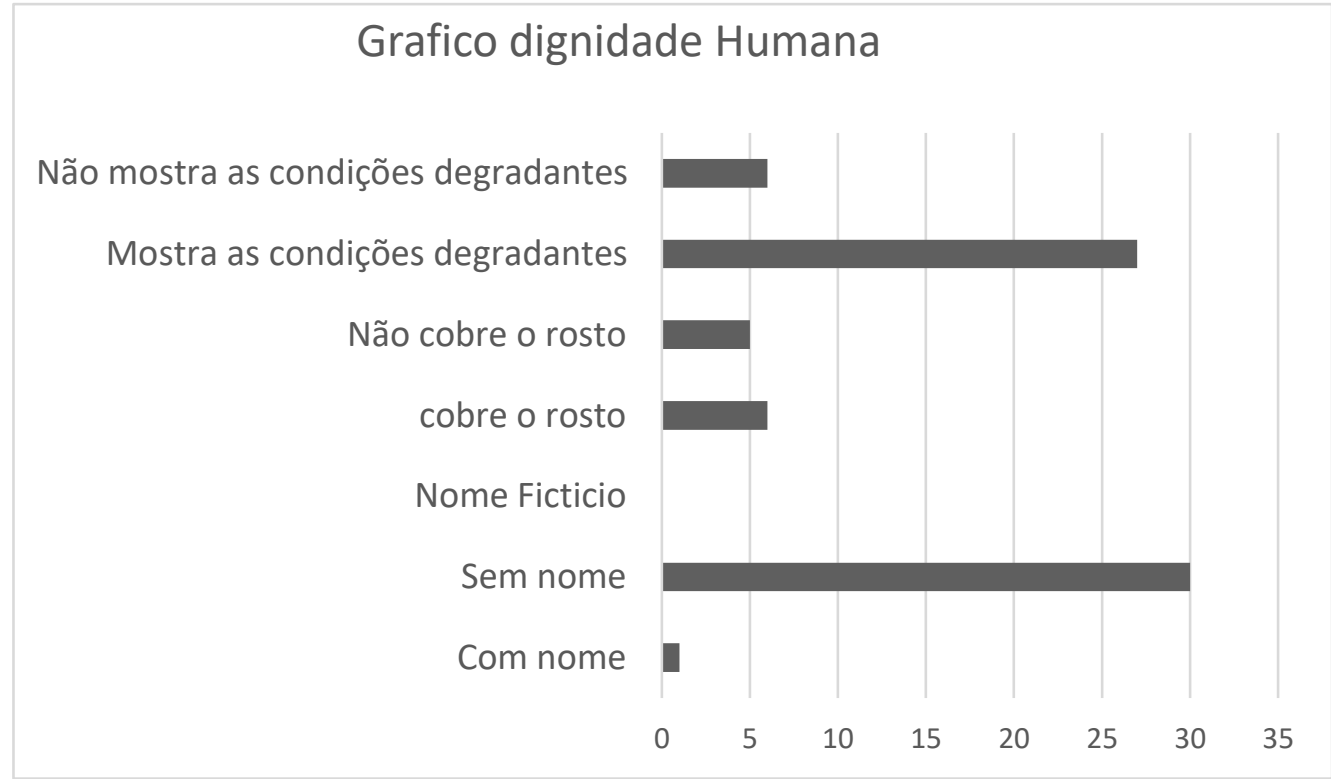

Fonte: Garcez (2019).

Nessa perspectiva ao longo da análise das notícias foi se identificado que a maioria das notícias não se tinha o nome das vítimas, e aquela que continham fotos metade não cobriam os rostos dos trabalhadores resgatados e em sua maioria mostravam as condições de trabalhos dos trabalhadores resgatados.

Em continuidade a analise quanto a dignidade humana, a partir da figura 5, fora retirada do portal Jornal Pequeno do dia 03 de maio de 2016. Relacionada ao processo do Ministério Público do Trabalho (MPT) a ocorrência no municipio de Imperatriz (MA), contra a Universidade Federal do Maranhão (UFMA), a construtora vinculada a instituição e ao diretor e empresário da mesma. 
Após manter trabalhadores em condições análogas à escravidão. Nessa reportagem os trabalhadores não foram nominalmente citados, porém é uma das poucas onde aparece o nome do empresário e da construtora responsáveis pela construção, além da instituição contratante.

Figura 5: Portal de notícias "Jornal Pequeno". Trabalhadores resgatados em situação análoga ao trabalho escravo no

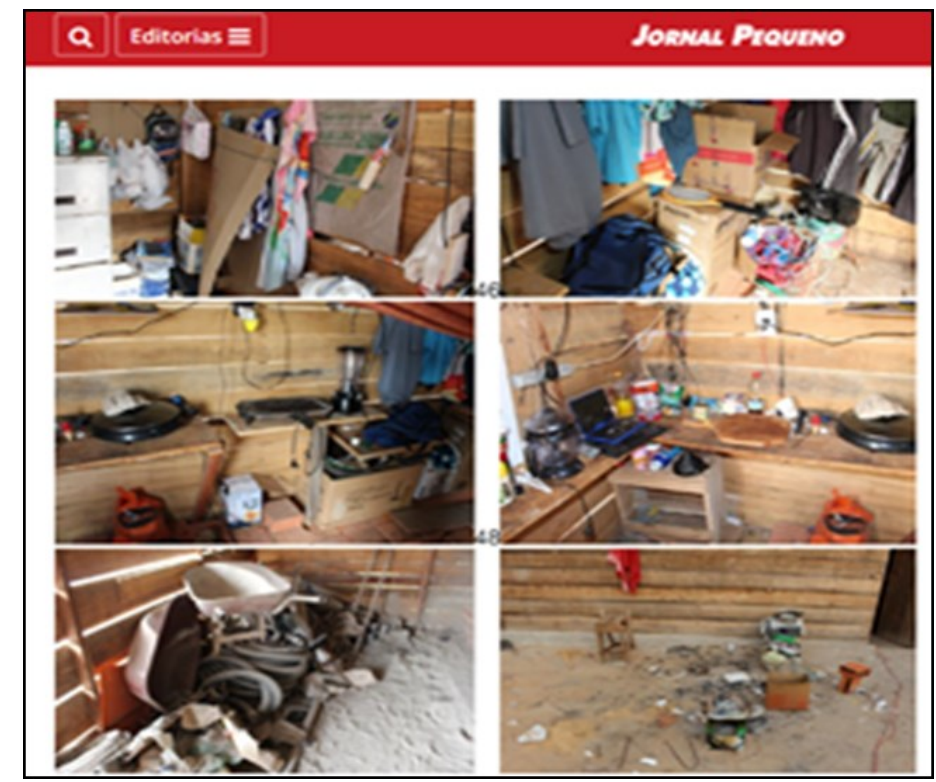

município de Imperatriz (MA). Notícia postada no dia 03 de maio de 2016.

Fonte: Portal de notícias “O Imparcial” (2016).

$\mathrm{Na}$ figura 6, extraída do jornal "O Imparcial” do dia 20 de dezembro de 2019, mostra a condição degradante de trabalhos, porém não é divulgado o nome das vítimas e não possui o nome dos escravagistas apontados pelo crime em questão. 
Figura 6: Jornal “O Imparcial”. Maranhenses resgatados do Piauí em situação de trabalho escravo. Notícia postada no dia 20 de dezembro de 2019.

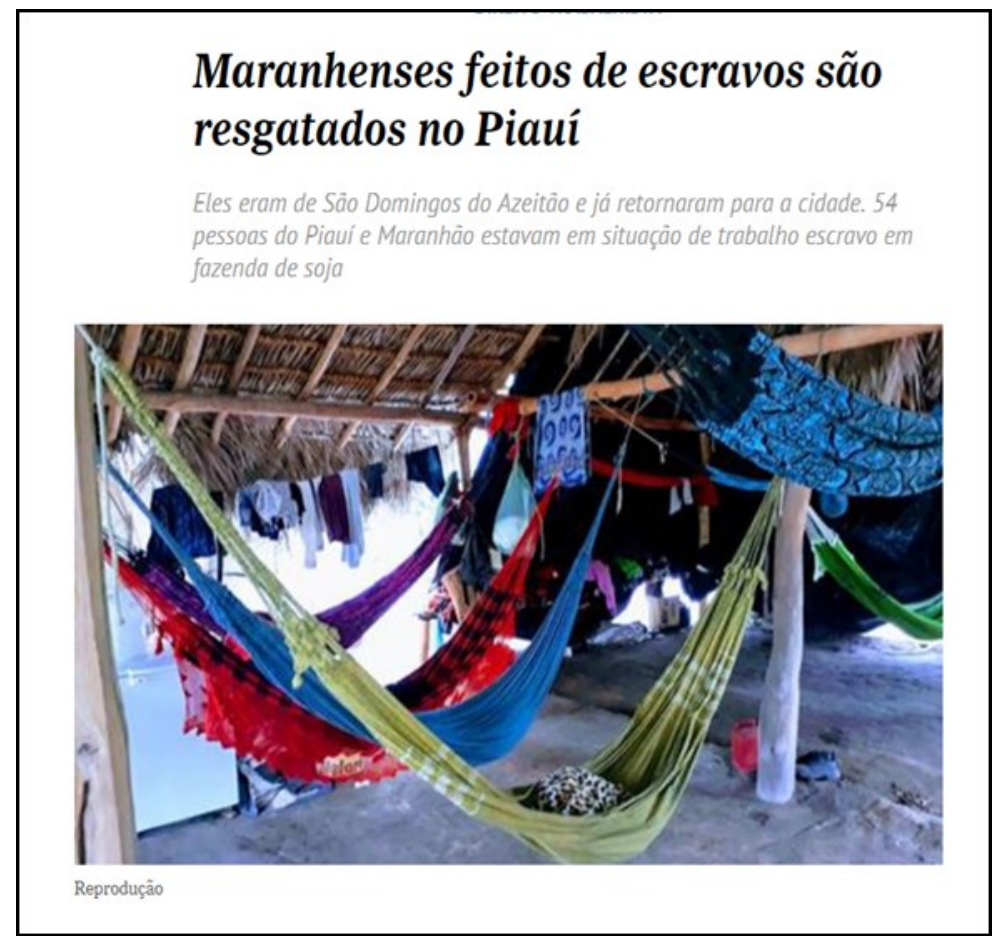

Fonte: Portal de notícias "O Imparcial” (2019).

A próxima reportagem, representada na figura 7, foi postada 19 de outro de 2017 . Essa reportagem do "O Imparcial" também não mostra o rosto dos trabalhadores, mas descreve as condições de trabalho em seu enunciado. Quantos casos ocorreram naquele ano, fazendo um grande balanço do anual com dados coletados junto aos órgãos responsáveis. 
Figura 7: Jornal “O Imparcial”. Levantamento dos casos de trabalho escravo no Maranhão. Notícia postada no dia 19 de outubro de 2017.

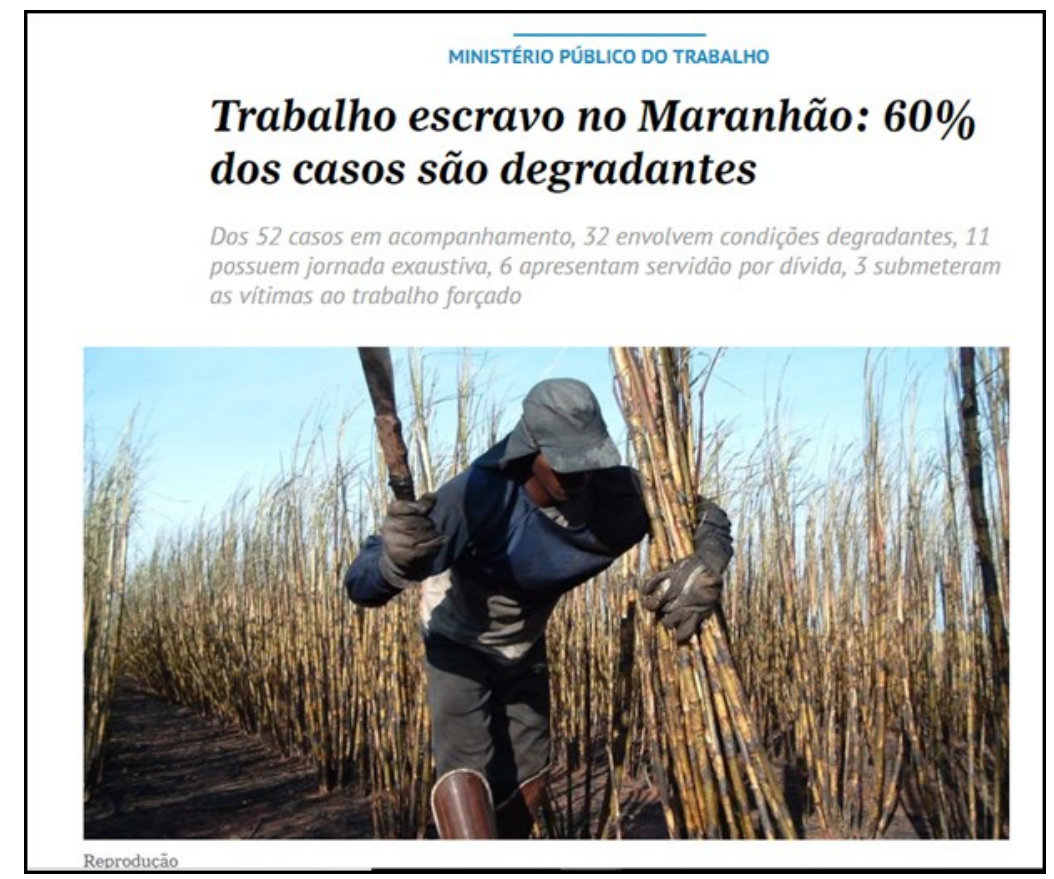

Fonte: Portal de notícias “O Imparcial” (2017).

Em continuidade a próxima categoria de análise, temos a aparição ou não dos nomes dos empregadores/escravagistas nas reportagens, o que acabou sendo um ponto interessante pois as reportagens que falavam o nome dos empregadores em comparação as que não falavam, manteve em um número equilibrado entre os jornais e portais de notícias. 
Figura 8: Números comparativos entre jornais e portais de notícia que divulgavam a aparição ou não dos nomes dos empregadores/escravagistas nas reportagens.

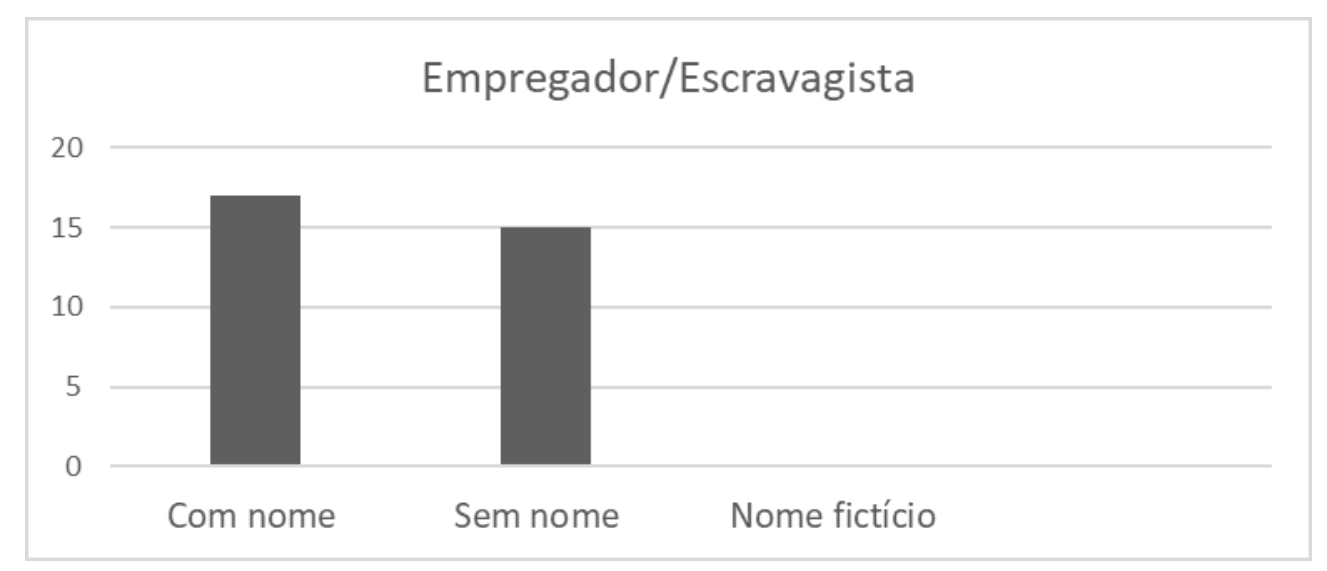

Fonte: Garcez (2019).

Outro ponto de análise parte do questionamento de onde esses trabalhadores foram resgatados. Visto que o Maranhão é o estado consolidado como maior exportado de mão de escravizada do país, mas também possui grandes indicies de trabalhadores mantidos em condições análogas à escravidão.

Figura 9: Levantamento dos trabalhadores resgatados conforme origem do trabalhador

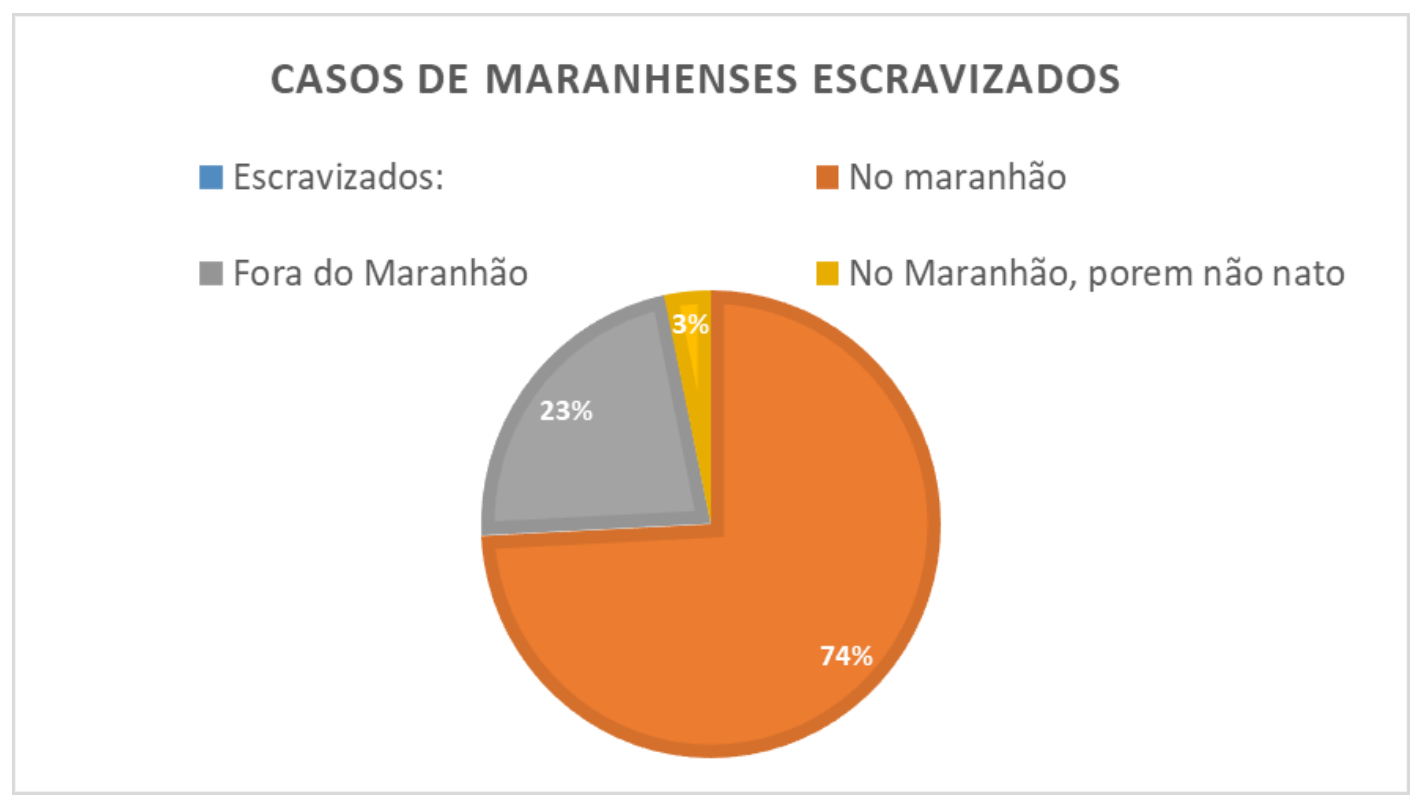

Fonte: Garcez (2019).

Esse fenômeno de origem pode ser explicado pelos índices de desenvolvimento humano do estado. Os grandes índices de analfabetos, grande concentração de terra, implicam diretamente na 
espacialização dos trabalhadores resgatados nos municípios maranhenses e fora do estado. As reportagens falam de resgatados em pelo menos 40 diferentes municípios maranhenses, alguns deles aparecendo mais de uma vez como Vargem Grande, Bacabal, Peritoró e Bom Jardim.

\section{CONSIDERAÇÕES FINAIS}

Essa pesquisa busca entender através meios de notícias (jornais e portais) como lugar de disputas discursivas que apresentam efeitos de recepção de um grupo social especifico, pois, o jornal tem um papel essencial na construção de narrativas. O poder aplicado a esse meio de comunicação é considerado como um "quarto poder" por muitos autores como Nelson Traquina (2005), apontando o jornalismo como a constituição do "quarto poder" devido a sua capacidade de investigar os outros poderes e de poder divulgar informações que permitam a existência da democracia. A representatividade na mídia é construída por vários discursos institucionais e organizados por uma normatização comum ao próprio jornalismo.

E em um segundo momento o papel dos jornais em mostrar para como esse tipo de trabalho se espalha no território maranhense e como esse trabalhador também é levado para outras estados e regiões do país. A expropriação do trabalhador do campo cria um exército de reservas, o trabalhador é visto como meio de produção, é separado de sua liberdade com o intuito de criar condições necessárias de produção de capital.

Partindo análise dessas notícias poderemos percebemos como esses trabalhadores são representados para a sociedade, se ele recebe ou não nome, se é tratado de forma digna ou apenas mais um número a ser inserido no sistema. Se se as notícias analisam as situações que esses trabalhadores são levados a se encontra em situação de tal vulnerabilidade. Se as matérias jornalísticas se importam em proteger os trabalhadores ou os escravagistas. Como essas matérias fazem a distribuição territorial dos regates desses trabalhadores. Essas analises nos levam a entender como a grande mídia vê e representa esses trabalhadores e qual o tipo de narrativa está sendo entregue a sociedade, através de qual imagem foi pintada o retrato da situação de exploração e degradação do trabalhador, que ocorre tanto no campo como na cidade, e ainda é visto com maus olhos pela população, seja pelo próprio desconhecimento sobre o trabalho escravo contemporâneo ou pela ganância do capital e dos seus dominantes adeptos a essa prática. 


\section{REFERÊNCIAS}

BRITTO FILHO, J.C.M de. Trabalho decente: analise jurídica da exploração, trabalho escravo e outras formas de trabalho indigno. 2. Ed. São Paulo: LTr, 2010.

KOVACH, Bill; ROSENSTIEL, Tom. Os elementos do jornalismo: o que os jornalistas devem saber e o público exigir. 2. Ed. São Paulo: Geração, 2004.

MARANHÃO. II Plano Estadual para Erradicação do Trabalho escravo no Maranhão. Secretaria dos Direitos Humanos e Participação Popular. Disponível em: $<$ http://escravonempensar.org.br/wp-content/uploads/2019/04/Plano-Estadual_MA_2012.pdf $>$.

Acesso em 16 de setembro de 2019.

MOURA, F.A. Trabalho Escravo e Mídia: olhares de trabalhadores rurais maranhenses. $1^{\circ}$ ed. São Luis: Ed. EDUFMA, 2016.

RODRIGUES, S. J. D. Trabalho escravo no Maranhão e vulnerabilidade do trabalhador. In: RODRIGUES, S.J.D.; et al. (Org.). Temas da Geografia do Maranhão: territórios e desenvolvimento regional, lugar, educação e cultura. $1^{\circ}$ ed. São Luis: Café \& Lápis; Edufma, 2017, p. 253-277.

SAKAMOTO, L. Os acionistas da casa grande: a reinvenção capitalista do trabalho escravo no Brasil contemporâneo. In: FIGUEIRA, R.R.; PRADO, A.A (Orgs.). Olhares sobre a escravidão contemporânea: novas contribuições críticas. Cuiabá: EdUFMT, 2011.

SEVERO, F. G. O trabalho escravo na acumulação capitalista moderna. In: RICARDO, R.F; et al. (Org.). Discussões contemporâneas sobre trabalho escravo: teoria e pesquisa. 1ed.Rio de Janeiro: Mauad X, 2016, v. 2016, p. 237-255.

SILVERSTONE, R. Porque estudar Mídia? São Paulo: Edições Loyola, 2002.

FRANÇA, V. O acontecimento e a mídia. Galaxia (São Paulo, Online), n. 24, p. 10-21, dez. 2012.

TRAQUINA, N. Teorias do Jornalismo. Florianópolis: Insular, 2004 - 2005. 2. Ed. Florianópolis: Insular, 2008. 2v.: ill. 